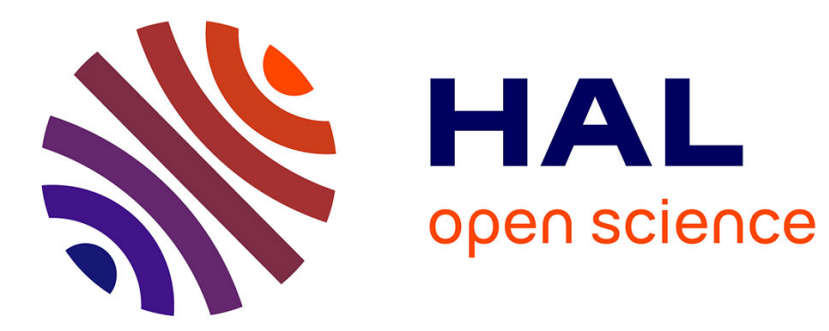

\title{
Delta Doping in Si and SiGe by LP(RT)CVD
}

\author{
B. Tillack, J. Schlote, G. Ritter, D. Krüger, G. Morgenstern, P. Gaworzewski
}

\section{To cite this version:}

B. Tillack, J. Schlote, G. Ritter, D. Krüger, G. Morgenstern, et al.. Delta Doping in Si and SiGe by LP(RT)CVD. Journal de Physique IV Proceedings, 1995, 05 (C5), pp.C5-1117-C5-1123. 10.1051/jphyscol:19955132 . jpa-00253829

\section{HAL Id: jpa-00253829 https://hal.science/jpa-00253829}

Submitted on 1 Jan 1995

HAL is a multi-disciplinary open access archive for the deposit and dissemination of scientific research documents, whether they are published or not. The documents may come from teaching and research institutions in France or abroad, or from public or private research centers.
L'archive ouverte pluridisciplinaire HAL, est destinée au dépôt et à la diffusion de documents scientifiques de niveau recherche, publiés ou non, émanant des établissements d'enseignement et de recherche français ou étrangers, des laboratoires publics ou privés. 
JOURNAL DE PHYSIQUE IV

Colloque C5, supplément au Journal de Physique II, Volume 5, juin 1995

C5-1117

\title{
Delta Doping in Si and SiGe by LP(RT)CVD
}

\author{
B. Tillack, J. Schlote, G. Ritter, D. Krüger, G. Morgenstern and P. Gaworzewski \\ Institute of Semiconductor Physics, Walter-Korsing-Straße 2, 15230 Frankfurt (Oder), Germany
}

\begin{abstract}
Sharp profiles of boron were prepared by Low Pressure (Rapid Thermal) Chemical Vapor Deposition (LP(RT)CVD). Two different approaches for the delta doping were used.

In the first case the dopants were incorporated into the growing film. The process was kinetically controlled. By this way B-delta-layers with a steepness of $1.7 \mathrm{~nm} /$ decade were measured by Secondary ion mass spectrometry (SIMS) for the profiles prepared.

In the second case the doping was performed during an interruption of layer growth. The process was controlled by the surface adsorption equilibrium of dopants. Using this regime B-delta-layers of 1 monolayer and with a steepness of $1.4 \mathrm{~nm} / \mathrm{dec}$ ade were obtained in SiGe.

The values of the estimated steepness represent an extremely sharp profile for a CVD process. Structural properties of the delta-doped layers were investigated using cross sectional transmission electron microscopy (XTEM).

The steepness estimated by SIMS was compared with high depth resolution spreading resistance (SR) measurements which detect the electrical active boron only.
\end{abstract}

\section{INTRODUCTION}

Boron doped $\mathrm{Si} / \mathrm{SiGe}$ heterostructures are of increasing importance because of their possible use for novel electronic and optoelectronic devices such as heterojunction bipolar transistors (HBTs), quantum well devices, infrared superlattice detectors [1].

Due to the problem of thermal stability and the critical thickness limitation which are connected with compressive strain within the SiGe layer low temperature techniques have to be used for the deposition. Moreover the deposition technique has to allow a proper control of composition and thickness of the thin, pseudomorphic SiGe layer and it has to be able to fabricate abrupt doping profiles down to an atomic level.

Beside molecular beam epitaxy (MBE) as an established technique to form steep doping profiles, different CVD techniques were used especially for boron in silicon (e. g. [2, 3]). Different growth modes are possible to form steep boron profiles. The cormmon procedure using CVD is to switch gase flows, temperature, or both in short time intervals during deposition [3]. In this case the boron is incorporated into the growing film.

A completely different approach to obtain sharp doping profiles is the so called atomic layer doping [4, 5]. In this case the epitaxial process is interrupted and the surface is exposed to the dopant gas. Then the epitaxy is continued.

In the paper presented both of the doping modes are discussed with the aim to demonstrate the capability of RTCVD to form steep boron profiles in SiGe and Si at conditions that enable an incorporation of $\mathrm{B}$ into the growing film and at conditions adequate to atomic layer doping. The steepness of the prepared boron profiles using the two growth modes were estimated by SMS [6]. By high depth resolution spreading resistance measurement the concentration of electrically active boron was investigated. 


\section{EXPERIMENTAL}

The Si and SiGe films were deposited using LP(RT)CVD from SiH $/ \mathrm{H}_{2}$ and $\mathrm{SiH}_{4} / \mathrm{GeH}_{4} / \mathrm{H}_{2}$ source gases, respectively.

In situ boron doping was performed by means of $\mathrm{B}_{2} \mathrm{H}_{6}$. Before deposition, a $\mathrm{H}_{2}$ prebake at $1000{ }^{\circ} \mathrm{C}$ was carried out to remove the native oxide at the surface of the Si substrate.

$\mathrm{SiGe}$ was deposited at a temperature of $500{ }^{\circ} \mathrm{C}$ and a total pressure of $200 \mathrm{~Pa}$. By changing the $\mathrm{SiH}_{4} / \mathrm{GeH}_{4}$ ratio, the $\mathrm{Ge}$ content in the $\mathrm{SiGe}$ layer was varied from $0 \%$ to about $30 \%$.

For the preparation of B profiles two different techniques were used. In the first case the B incorporation into the growing $\mathrm{Si} / \mathrm{SiGe}$-film was performed in dependence on Ge content, growth temperature, and time of doping. In the second case, the B doping was performed using conditions without Si/SiGe layer growth. For this purpose the epitaxy was interrupted by switching off the heater. Then, the temperature was increased up to $350{ }^{\circ} \mathrm{C}$ again and the surface was exposed to $\mathrm{B}_{2} \mathrm{H}_{6} / \mathrm{H}_{2}$ and $\mathrm{SiH} / \mathrm{GeH}_{4} / \mathrm{B}_{2} \mathrm{H}_{6} / \mathrm{H}_{2}$, respectively. Because of the very small deposition rate at this low temperature there was no layer growth even in the presence of $\mathrm{SiH}_{4}$ and $\mathrm{GeH}_{4}$.

After exposure of the surface with $\mathrm{B}_{2} \mathrm{H}_{6}$ the higher growth temperature was readjusted and the epitaxial process was continued.

The SIMS measurements were performed to find out depth profiles of using an ion microprobe ATOMIKA 6500. The experiments reported here were carried out with mass-filtered oxygen ions at different energies from 3 to $9 \mathrm{keV}$. The focused beam was scanned in spiral mode over areas of typically $300 \mu \mathrm{m}^{2}$ squared at normal incidence.

To characterize the net concentration of electrically active dopants, high depth resolution spreading resistance measurements were carried out.

TEM cross section investigations were used to measure the width and the depth position of the boron peaks and to characterize the crystalline perfection of the deposited films.

\section{RESULTS AND DISCUSSION}

\subsection{Kinetically controlled incorporation of boron}

During the deposition of $\mathrm{Si}$ or SiGe the boron is incorporated into the growing film using $\mathrm{B}_{2} \mathrm{H}_{6}$ as source gas.

Fig. 1 shows a result of $B-\delta$ doping of $S i$ at a temperature of $\mathrm{T}=550^{\circ} \mathrm{C}$ for $30 \mathrm{sec}$.

An exponential decay length of about $1.7 \mathrm{~nm} /$ decade and a peak concentration of about $1.5 \times 10^{20} \mathrm{~cm}^{-3}$ were detected by SIMS measurements. By XTEM analysis (Fig. 1b) a thickness of the B-doped layer of $1.6 \mathrm{~nm}$ was estimated. Typical values for exponential decay length obtained by CVD are in the region of a few $\mathrm{nm} / \mathrm{dec}$ (e. g. [3,7]). The value of $1.7 \mathrm{~nm} / \mathrm{dec}$ represents an extremely sharp B doping profile in Si for CVD and MBE $[2,8]$.

In the case of incorporation of boron into the growing film, it is substantial to know the influence of $\mathrm{B}_{2} \mathrm{H}_{6}$ on the deposition characteristics, such as deposition rate and composition. In contrast to the $\mathrm{GeH}_{4} / \mathrm{SiH}_{2} \mathrm{Cl}_{2} / \mathrm{B}_{2} \mathrm{H}_{6}$ reaction system for which a higher deposition rate of doped SiGe was reported [9] compared with undoped films, the influence of the $\mathrm{B}_{2} \mathrm{H}_{6}$ partial pressure on the deposition rate seems to be neglectable for the $\mathrm{GeH}_{4} / \mathrm{SiH}_{4} / \mathrm{B}_{2} \mathrm{H}_{6}$ reaction system [10].

The incorporation of boron into $\mathrm{Si}$ and $\mathrm{SiGe}$ during deposition increases linearly with the $\mathrm{B}_{2} \mathrm{H}_{6}$ partial pressure $[3,10]$.

In the temperature range between $500^{\circ} \mathrm{C}$ and $650^{\circ} \mathrm{C}$ about the same value was found for the activation energies of deposition of both undoped $(1.3 \mathrm{eV})$ and B-doped $(1.4 \mathrm{eV}) \mathrm{SiGe}$. Therefore one can expect that there is the same temperature dependence, independendly on the $\mathrm{B}_{2} \mathrm{H}_{6}$ partial pressure.

Moreover the deposition rate increases with increasing $\mathrm{GeH}_{4}$ partial pressure [11]. By this way the $\mathrm{GeH}_{4}$ partial pressure and the temperature are influencing the deposited film thickness (deposition rate) while there should be no influence on the boron concentration. 
a.

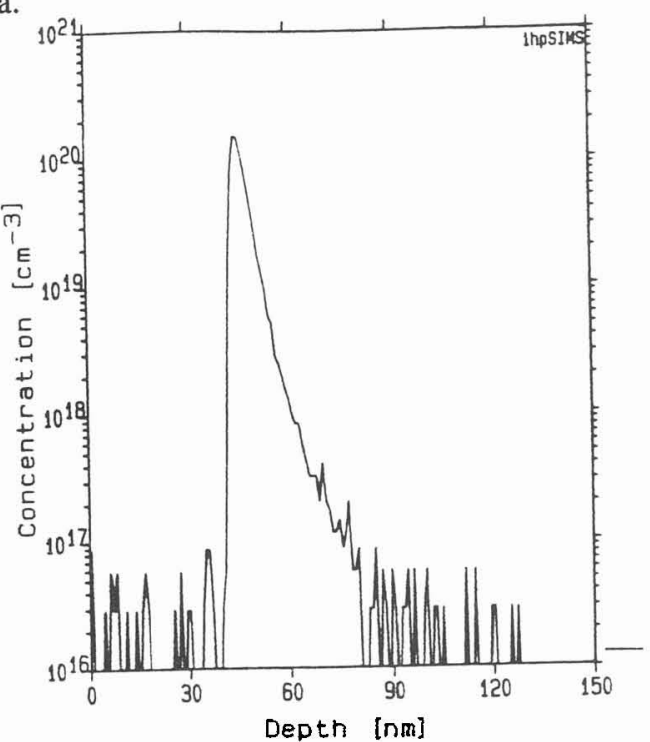

b.

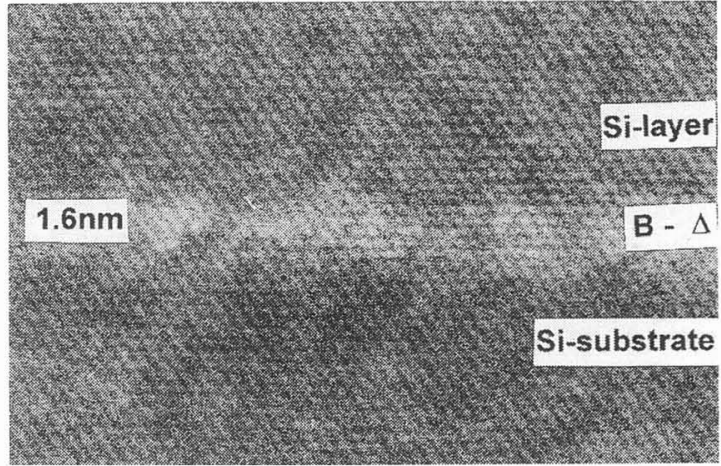

Fig. 1: SIMS profile (a) and XTEM image (b) of B- $\delta$-layer within Si (deposition temperature $\mathrm{T}=550^{\circ} \mathrm{C}$ )

Based on these assumption the influence of Ge content, deposition temperature, $\mathrm{B}_{2} \mathrm{H}_{6}$ partial pressure, and doping time on the $\mathrm{B}-\delta$ doping were investigated.

In fig. 2 the result concerning the dependence of the maximum peak concentration of boron on the Ge content of the SiGe film is shown. The Ge content was varied by changing the $\mathrm{GeH}_{4}$ partial pressure keeping all other deposition parameters constant.

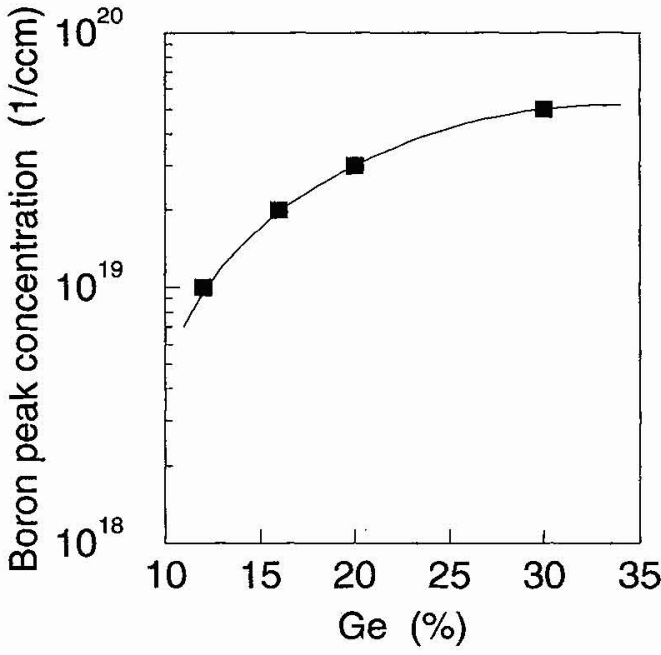

Fig. 2: Boron peak concentration (SIMS) for the deposition of SiGe with different Ge content, deposition temperature $500^{\circ} \mathrm{C}$

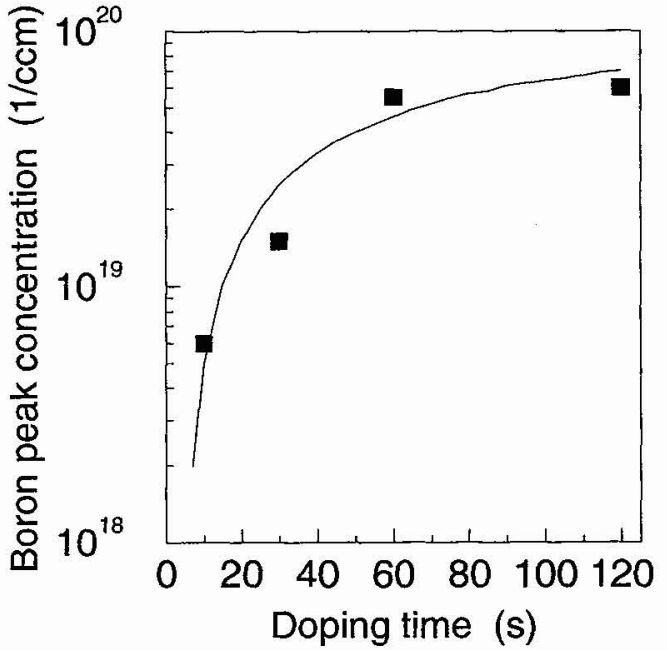

Fig. 3: Boron peak concentration (SIMS) for deposition of $\mathrm{SiGe}(20 \% \mathrm{Ge})$ in dependence on the doping time, deposition temperature $500^{\circ} \mathrm{C}$ 
However the maximum peak concentration of $B$ increases with increasing Ge content. This result corresponds to investigation of $B$ layer doping [10] where the increased boron incorporation due to the Ge content in the SiGe has been discussed as a result of a higher surface adsorption rate of B-hydrides on Ge atoms than on Si atoms.

Fig. 3 demonstrates the dependence of the B peak concentration on the doping time for a SiGe film containing $20 \% \mathrm{Ge}$. A typical saturation behaviour was found. This could be explained by assuming a transition period for the reaction which is required for reaching the surface adsorption equilibrium of Bhydride.

Figure 4 shows the boron peak concentration in dependence on the temperature. The expected, constant $B$ peak concentration has been found for deposition at higher temperature only $\left(T \geq 550^{\circ} \mathrm{C}\right)$. For boron profiles in SiGe $(20 \%)$ deposited at different temperatures the $\mathrm{B}$ peak concentration increases from $\mathrm{T}=$ $400{ }^{\circ} \mathrm{C}$ up to $\mathrm{T}=550{ }^{\circ} \mathrm{C}$. A TEM cross section investigation demonstrates that only at higher temperatures $\left(550^{\circ} \mathrm{C}\right.$ and $600^{\circ} \mathrm{C}$ ) thin doped SiGe films were grown. The measured film thicknesses were $3.6 \mathrm{~nm}$ and $11.0 \mathrm{~nm}$ for $\mathrm{T}=550^{\circ} \mathrm{C}$ and $\mathrm{T}=600^{\circ} \mathrm{C}$ respectively. These values are in accordance with the thickness expected taking into account the nominal deposition rates at the used temperatures. For the boron peaks deposited at lower temperature $\left(500^{\circ} \mathrm{C}, 450^{\circ} \mathrm{C}\right.$ and $\left.400^{\circ} \mathrm{C}\right)$ the TEM analysis indicates a contrast between the bottom and cap layers typical for a covered interface. Obvious, there was no layer growth because of the very low deposition rate and the short deposition time. The peak concentration is mainly determined by the B-hydride surface adsorption equilibrium for the experimental conditions used (temperature, partial pressures). Therefore, the determined temperature dependence suggests an equilibrium behaviour rather than a kinetic control for the experimental conditions used.

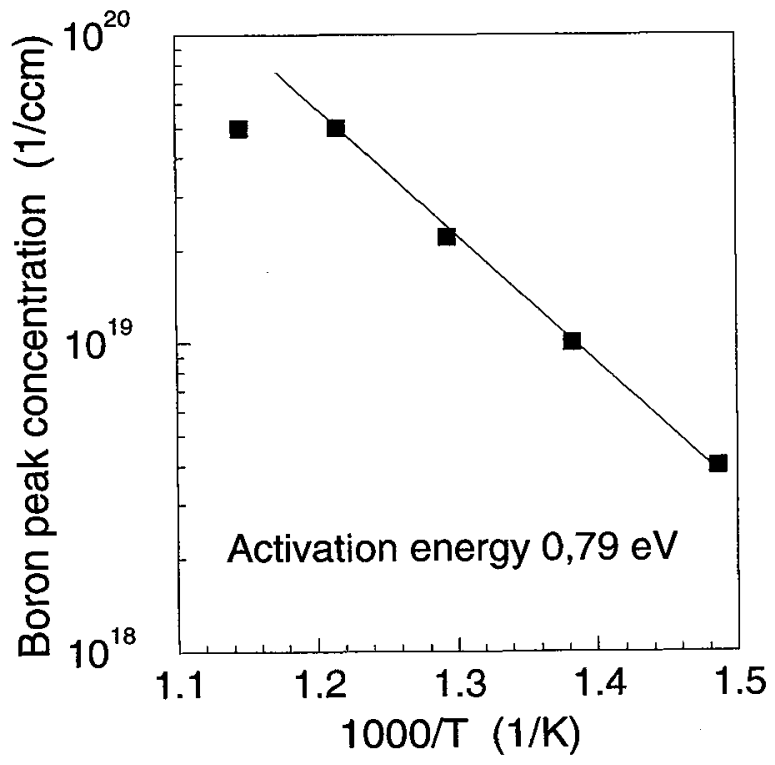

Fig. 4: Temperature dependece of boron peak concentration in $\mathrm{SiGe}(20 \% \mathrm{Ge})$

For the temperature dependence shown in figure 4 an effective activation energy of $0.79 \mathrm{eV}$ was estimated. The value for $\mathrm{T}=600^{\circ} \mathrm{C}$ falls out of the correlation. It can be supposed, that here the kinetic control becomes dominating. At the present stage, we cannot yet determine the elemental process for the observed effective activation energy. Two possible processes which can be considered are the adsorption of B-hydride at the surface and the thermal decomposition of $\mathrm{B}_{2} \mathrm{H}_{6}$ which delivers the $\mathrm{B}$-hydride for adsorption. However, for the thermal decomposition the activation energy is higher (1.1 eV [12]). Taking into account that the measurements were done in a transition area between equilibrium control and kinetic control of the reaction, further experiments are necessary. 


\subsection{Surface adsorption equilibrium controlled incorporation of boron}

Already the results discussed in the chapter before for the B- $\delta$-doping at low temperature as well as at short time intervals suggest an equilibrium control rather than a kinetic control. The experimental conditions used in these cases result in a very low deposition rate.

Based on these results the $\mathrm{B}$ incorporation in $\mathrm{Si}$ and $\mathrm{SiGe}$ were investigated at deposition conditions dominated by the surface adsorption equilibrium. For this purpose the boron was incorporated during an interruption of epitaxial growth caused by decreasing the deposition temperature. Then the surface was exposed to $\mathrm{SiH}_{4} / \mathrm{H}_{2} / \mathrm{B}_{2} \mathrm{H}_{6}$ and $\mathrm{B}_{2} \mathrm{H}_{6} / \mathrm{H}_{2}$ for boron in $\mathrm{Si}$ or $\mathrm{SiH}_{4} / \mathrm{GeH}_{4} / \mathrm{H}_{2} / \mathrm{B}_{2} \mathrm{H}_{6}$ and $\mathrm{B}_{2} \mathrm{H}_{6} / \mathrm{H}_{2}$ for boron in $\mathrm{SiGe}$, respectively. In fig. 5 the SIMS measurements of B-profiles in Si and SiGe are represented. Three peaks were prepared for both cases. The exposure time was $240 \mathrm{~s}$ at a temperature of $350^{\circ} \mathrm{C}$ for every peak. During the exposure time for the first and second peak $\mathrm{SiH}_{4}$ and $\mathrm{SiH}_{4} / \mathrm{GeH}_{4}$ were present in addition to $\mathrm{B}_{2} \mathrm{H}_{6} / \mathrm{H}_{2}$, respectively. Peak (1) differs from peak (2) by a smaller $\mathrm{H}_{2}$ partial pressure. For the preparation of the third peak the surface was exposed to $\mathrm{B}_{2} \mathrm{H}_{6} / \mathrm{H}_{2}$ only. For this profile the highest partial pressure of $\mathrm{B}_{2} \mathrm{H}_{6}(5.5 \mathrm{~Pa})$ was used. The resulting peak concentration was about $5 \times 10^{20} \mathrm{~cm}^{-3}$ for both $\mathrm{Si}$ and SiGe. The integrated boron concentration is $7.6 \times 10^{14} \mathrm{~cm}^{-2}$ for Si and $6.9 \times 10^{14} \mathrm{~cm}^{-2}$ for SiGe. This means about 1 monolayer boron was deposited. An exponential decay length of $1.4 \mathrm{~nm} / \mathrm{dec}$ was found.

a.

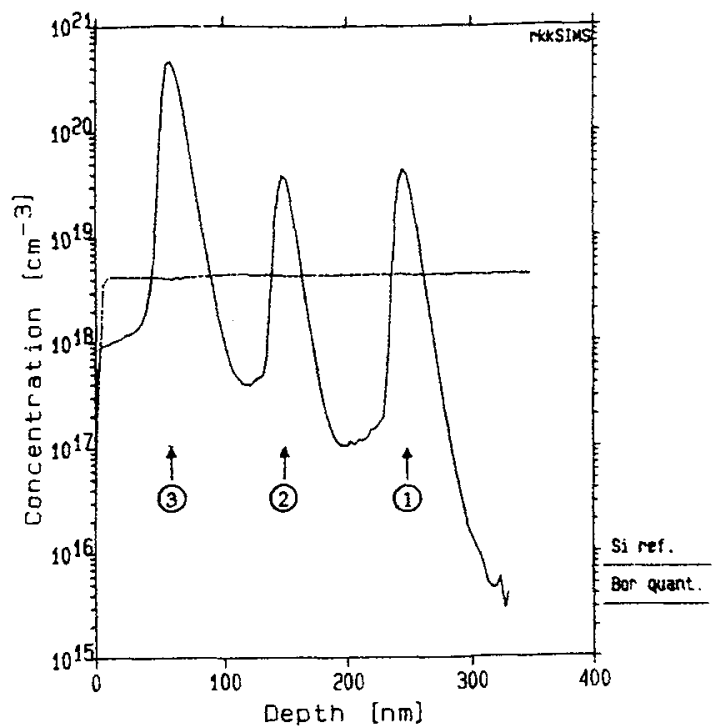

b

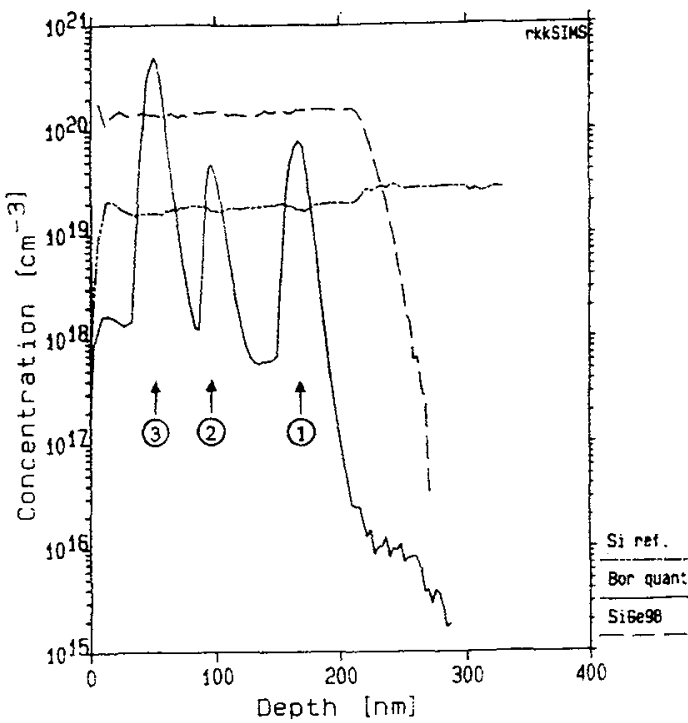

Fig. 5: SIMS measurement of three B-peaks in Si (a) and SiGe (20\%) (b). The B was incorporated during an interruption of layer growth at $\mathrm{T}=350^{\circ} \mathrm{C}$ for $240 \mathrm{~s}$

If the partial pressure of $\mathrm{B}_{2} \mathrm{H}_{6}$ is decreased the boron concentration decreases too because of a changed surface adsorption equilibrium. Simultaneously the $\mathrm{H}_{2}$ partial pressure was changed. In this case $\mathrm{H}_{2}$, $\mathrm{SiH}_{4}$ or $\mathrm{H}_{2} / \mathrm{SiH}_{4} / \mathrm{GeH}_{4}$ have been competing with $\mathrm{B}$-hydride in surface adsorption. For boron in $\mathrm{Si}$ the concentration seems to be independent on the $\mathrm{H}_{2}$ partial pressure used for peak (1) and (2)

Contrary to this result the boron peak (1) and (2) in SiGe differ distinctly. For the higher partial pressure of $\mathrm{H}_{2}$ a higher $\mathrm{B}$ concentration was observed. The $\mathrm{SiH}_{4}$ and $\mathrm{GeH}_{4}$ partial pressures were equal for both peaks. So the Ge content had the same value of about $20 \%$. The reason for this finding is not clear yet.

The SIMS results discussed were confirmed by cross sectional TEM investigations.

Fig. 6 shows the TEM micrographs of the three B- $\delta$-layers in $\mathrm{Si}$ and SiGe, respectively, corresponding to the SIMS profiles of fig. 5. In both cases the depth positions of the B-peaks (1) and (2) were only visible as a contrast typical for a covered interface. The width values of the peaks were not measurable.

In the case of $B$ in Si there were narrow defect zones $8.4 \mathrm{~nm}$ and $7.1 \mathrm{~nm}$ in width for peak (1) and (2), 
respectively. These zones contain microprecipitates and stacking faults as nucleation centers for the growth of extended defects (twins and stacking faults) through the entire films. SIMS measurements demonstrated that the appearance of these defects were not related to an increased oxygen concentration. In some cases the microprecipitates could be identified as boron precipitates measuring the distance between lattice planes using high resolution TEM.

a.

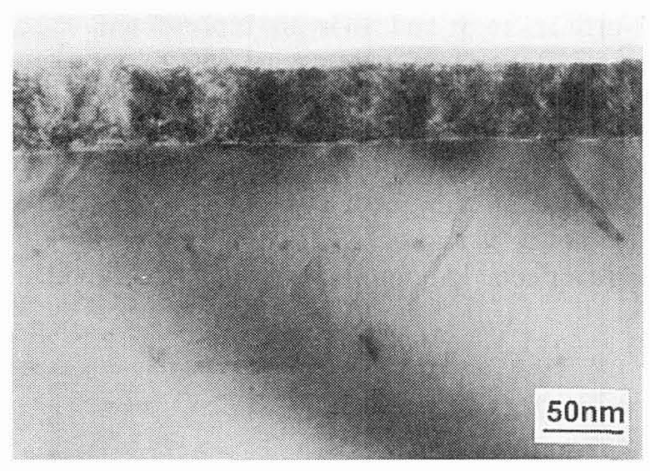

b.

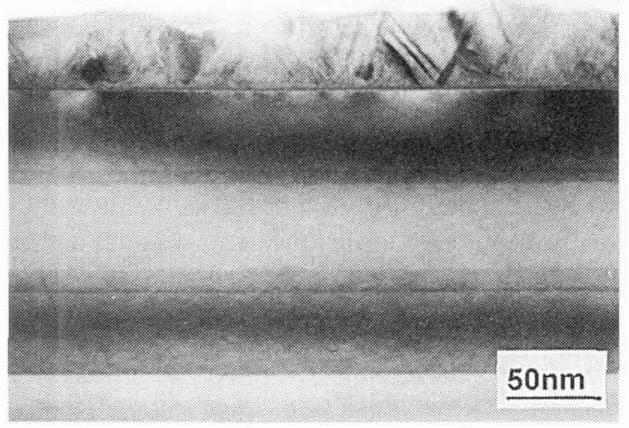

Fig. 6: XTEM image of three B-peaks in Si (a) and SiGe (20\% Ge) b corresponding to the SIMS measurement (Fig. 5)

In contrast to the $\mathrm{Si}$ the SiGe films deposited onto B peak (1) and (2) were of high crystalline perfection. This different behaviour can be explained taking into account a different stress situation of $\mathrm{B}$ in $\mathrm{Si}$ and in $\mathrm{SiGe}$. In the case of $\mathrm{Si}$ the incorporation of boron increases the stress within the film resulting in the formation of defects.

Contrary the incorporation of boron into $\mathrm{SiGe}$ reduces the stress already existing in the layer because of the Ge content.

The Si and SiGe film grown onto the B peak (3) were polycrystalline.

The B coverage of about $1 \mathrm{ML}$ of the surface in the case of peak (3) seems to be responsible for the nonepitaxial growth of the Si and SiGe cap layers, respectively.

In accordance with this result, the high depth resolution spreading resistance measurements demonstrate that the B peaks (1) and (2) are electrical active as well in Si as in SiGe. This means that even at the very low temperature of about $350^{\circ} \mathrm{C}$ the boron is incorporated electrically active. There was no electrical active $B$ concentration in the depth position of peak (3. Estimating the exponential decay length from the electrical active $B$ concentration profile a value of about $1.2 \mathrm{~nm} / \mathrm{dec}$ was obtained which agrees with that one measured by SIMS.

\section{SUMMARY AND CONCLUSIONS}

B- $\delta$-doping was performed in Si and in SiGe layers grown by Low Pressure (Rapid Thermal) Chemical Vapor deposition. Two different growth modes were used. In the first case the boron is incorporated into the growing film and the process is kinetically controlled. The boron peak concentration was found to be dependent on $\mathrm{Ge}$ concentration, doping time and doping temperature. Because of the low deposition rate used the results were explained taking into account a transition behaviour between equilibrium and kinetic control. Using this growth mode B- $\delta$-profiles with a steepness of $1.7 \mathrm{~nm} / \mathrm{dec}$ were obtained. In the second case the boron incorporation was performed during an interruption of layer growth. The process is controlled by the surface adsorption equilibrium. B- $\delta$-layers with a steepness of $1.4 \mathrm{~nm} / \mathrm{dec}$ were prepared at $350^{\circ} \mathrm{C}$. High depth resolution spreading resistance measurements demonstrate that the $\mathrm{B}$ incorporated at this low temperature in electrical active. 


\section{References}

[1] Wang K. L., and Karunasiri R. P. G., J. Vac. Sci. Technol. B 11 (3) (1993) 1159 - 1167

[2] Dutartre D., Warren P., Sagnes I., Badoz P. A., Perio A., Dupuis J. C., Prudon G., J. Vac. Sci. Technol. B 11 (1993) 1134 - 1139

[3] Roksnoer P. J., Maes J. W. F. M., Vink A. T., Vriezema C. J., Zalm P. C., Appl. Phys. Lett. 18 (7) (1991) $711-713$

[4] Grützmacher D. A., Eberl K., Powell A. R., Ek B. A., Sedgwick T. O., Iyer S. S., Thin Solid Films 225 (1993) 163 - 167

[5] Nishizawa J., Aoki K., Suzuki S., Kikuchi K., J. Cryst. Growth 99 (1990) 502 - 502

[6] Tillack B., Ritter G., Krüger D., Zaumseil P., Morgenstern G., 1. Int. Conf. on Materials for Microelectronics 17. - 19. October 1994, Barcelona, Spain

[7] Kircher R., Furuno M., Murota J., Ono S., J. De Phys. IV 1 (1993) 787 - 794

[8] Dowsett M. G., Barlow R. D., Fox H. S., Kubiak R. A. A., Collins R., J. Vac. Sci. Technol. B 10 (1992) 336 - 341

[9] Campbell S. A., Liu W. H., Leighton J. D., J. Vac. Sci. Technol. B 11 (3) (1993) 1129 - 1133

[10] Murota J., Honma F., Yoshida T., Goto K., Maeda T., Aizawa K., Sawada Y., J. de Physique IV 3 (1993) $427-432$

[11] Meyerson B. S., Uram K. J., Lagones F. K., Appl. Phys. Lett. 53 (1988) 2555 - 2557

[12] Greenwood N. N. in Comprehensive Inorganic Chemistry, edited by J. C. Bailar, H. J. Emeleus, R. Nyholm and A. F. Trorman-Dickenson (Pergamon, Oxford, 1973) Vol. 1 p. 770 